\title{
Effects of Vitamin D3 Deficiency on Performance in Football Players
}

\section{Khadijeh J. Menai ${ }^{1}$, Ali Irani' ${ }^{2}$, Roli Dave ${ }^{3}$}

Section: Healthcare

Sci. Journal Impact

Factor: 6.1 (2018)

ICV: 90.90 (2018)

(c) (i) (3)

Copyright@IJCRR
'Ph.D. Student, NMIMS Sunanda Divatia School of Science, V.L. Mehta Road, Vile Parle (W), Mumbai-400o56, India; ${ }^{2}$ Ph.D.; HOD Physiotherapy Dean, NMIMS Sunanda Divatia School of Science, HOD, Department of Physiotherapy and Sports Medicine, Nanavati Super Specialty Hospital, SV Road, Vile Parle (W), Mumbai-400056, India; ${ }^{N}$ MIMS Sunanda Divatia School of Science, V.L. Mehta Road, Vile Parle (W), Mumbai-400056, Consultant Physiotherapist Dr L H Hiranandani Hospital, Powai, Mumbai 400076, India.

\section{ABSTRACT}

Introduction: Football is a sport where speed and kicking performance are of utmost importance for most of the actions during the sport. Such intense actions require vitamin $D$ at optimal levels. There is a global prevalence of vitamin D deficiency even in countries with ample sunlight, India being an example.70\%-100\% of the general population in India is considered to have low vitamin $\mathrm{D}$ levels. Very few studies have aimed at finding out the vitamin $\mathrm{D}$ status in sportsmen while maximum studies have addressed the community in general.

Objective: The study aims at finding out the prevalence of vitamin D3 deficiency along with the effects of its deficiency on the kicking performance in football players.

Methods: This experimental study was carried out on 150 elite level football players from local clubs and academies across Mumbai city. All the subjects went through a screening blood test to determine vitamin D3 levels. Performance parameters were analyzed by assessing side kick distance, instep kick distance and kick velocity both at the beginning and end of 4 weeks supplementation.

Results: Paired T-test was used to analyze the data which showed statically significant improvement in sidekick distance, instep kick distance and kick velocity post 4 weeks of vitamin D3 supplementation. About $87 \%$ players recorded vitamin D3 levels < 30 $\mathrm{ng} / \mathrm{ml}$ (nanograms/milliliter) and 99\% players recorded vitamin D3 $<40 \mathrm{ng} / \mathrm{ml}$ (nanograms/milliliter).

Conclusion: We concluded that the vitamin D3 level in professional football players in Mumbai city is far below optimal. Supplementation may improve their performance and speed in terms of kick distance and kick velocity.

Key Words: Sidekick distance, Instepkick distance, Kick velocity, Vitamin D deficiency

\section{INTRODUCTION}

Football is a popular team sport enjoyed and played by many people around the globe. Football as a sport is constantly emerging and influencing young athletes to be taken up as a profession not only in India but around the world. It is a sport which requires the player to make numerous explosive moves, like kicking, tackling, jumping, sprinting and changing pace. ${ }^{1}$ Football is a sport where speed and kicking performance are of utmost importance for most of the actions during the sport. The sport requires performing intense actions all of which exacerbate the physical demands imposed on the player. Repeated sprints, stops, jumps are required to be performed throughout the game with maximum force. Hence the most crucial fit- ness criteria are the capacity of lower limb muscles to produce maximum power during the match. ${ }^{2}$ Such intense movements require vitamin $\mathrm{D}$ at optimal levels. Vitamin $\mathrm{D}$ belongs to the category of fat-soluble vitamin. There is a global prevalence of vitamin D deficiency even in countries with ample sunlight, India is an example. Athletic as well as non-athletic population both show the equal prevalence of vitamin D deficiency. Despite vitamin D deficiency being pandemic, it is the most underdiagnosed and undertreated nutritional deficiency globally. ${ }^{3} 70 \%-100 \%$ of the general population in India is considered to have low vitamin D levels. ${ }^{4}$ While data in terms of vitamin D status in elite athletic population is less, recent researches suggest that vitamin D has a crucial role in an athlete's health and performance. ${ }^{5}$ A prevalence ranging from $50 \%$

\section{Corresponding Author:}

Dr. Khadijeh J. Menai, Ph.D. Student, NMIMS Sunanda Divatia School of Science, V.L.Mehta Road, Vile Parle (W), Mumbai-400056, India.

ISSN: 2231-2196 (Print)

Received: 05.08.2020
ISSN: 0975-5241 (Online)

Revised: 24.09 .2020
Accepted: 02.11.2020

Published: 14.12 .2020 
to $94 \%$ was reported by community-based Indian studies done on healthy controls. ${ }^{6}$

Vitamin D plays an important role in immune response, muscle function, and musculoskeletal regulation. It is also required for maintaining normal blood calcium and phosphate levels vital for efficient muscle contraction and bone mineralization. It is mainly synthesized following incidental exposure of the skin to UVB radiations with a wavelength of 290-320 nm. It mainly exists in the form of cholecalciferol also known as vitamin D3. Vitamin D is mainly synthesized in the skin on sun exposure. ${ }^{7}$ One of the factors having a dramatic effect on the cutaneous synthesis of vitamin D is the use of sunscreen and the presence of dark skin. $99 \%$ of vitamin D synthesis is blocked due to melanin in the skin. ${ }^{8}$ As per the guidelines given by the US endocrine society vitamin D levels of $<20 \mathrm{ng} / \mathrm{ml}$ (nanograms/millilitre) considered deficiency, $21-29 \mathrm{ng} / \mathrm{ml}$ is considered insufficiency, $>30 \mathrm{ng} / \mathrm{ml}$ is considered sufficiency. The desirable and safe range of vitamin D would be $30-100 \mathrm{ng} / \mathrm{mL}$

Hence vitamin D levels of more than $30 \mathrm{ng} / \mathrm{ml}$ are considered desirable worldwide. ${ }^{9}$ Vitamin D deficiency has globally impacted all age groups as per these cut-offs. However, vitamin D level of at least $50 \mathrm{ng} / \mathrm{ml}$ is required to have a desirable and optimal athletic performance for any sportsman

.${ }^{10}$ The exact cut-off for the amount of vitamin $\mathrm{D}$ required for peak sports performance is still debatable. Controversy still exists regarding the exact cut-off of vitamin D deficiency. Owing to the lengthy nature of the sports nutrient loss may be greater in football players compared to the other fields of sports. Athletes with musculoskeletal pain and stress fracture should especially be considered for the diagnosis of lack of vitamin D. ${ }^{10,11}$

Very few studies have aimed at finding out the vitamin D status in sportsmen while maximum studies have addressed the community in general. The present literature shows scarcity of research showing us the impact of vitamin D on athletic performance in football players and whether sufficient vitamin D levels can help improve performance parameters. Hence the present study aims at finding out the effects of vitamin D3 deficiency on the kicking performance along with finding out the prevalence of vitamin D3 deficiency in football players. ${ }^{1,12}$

\section{MATERIALS AND METHODS}

This experimental study carried out on 150 elite level football players with a minimum of 2 years of playing experience between 18-35 years of age group. The study was performed with strict accordance with the ethical guidelines of NMIMS University. Local clubs and football academies were approached across the city of Mumbai which included Oil and Natural Gas Corporation (ONGC) football team, Central
Bank of India (CBI) football team, Air India football team, Conquers FC (football club), Andheri Football Academy (AFA), West Zone United FC (football club). All the teams were approached between the in-season period from October 2016to March 2019. Written informed consent was taken from individual player meeting the inclusion criteria with at least 2years of playing experience and training at least thrice a week. Players were excluded if they had any history of recent injury or surgeries in the past or were already diagnosed with vitamin D3 deficiency and were put on medications for the same.

Players were selected according to the inclusion criteria. The levels of vitamin D3 were determined by a blood test. A random blood sample was drawn in plain vials and serum separated. Vitamin D3 assay was carried out on Beckman Coulter Access 2 Chemiluminescence Immuno Assay (CLIA) automated processor. Vitamin D3cut-offs was considered as follows (table 1).

\section{Table 1: Vitamin $\mathrm{D}_{3}$ cut-off ranges}

\begin{tabular}{ll}
\hline $25(\mathrm{OH}) \mathrm{D}_{3}$ levels & Interpretation \\
$<20 \mathrm{~g} / \mathrm{ml}$ & Deficient \\
$\mathbf{2 0}-40 \mathrm{Ong} / \mathrm{ml}$ & Insufficient \\
$40-100 \mathrm{ng} / \mathrm{ml}$ & Sufficient \\
$>100 \mathrm{ng} / \mathrm{ml}$ & Toxicity \\
\hline
\end{tabular}

All the players were then referred to a physician wherein their vitamin D3 levels were clinically assessed. Post assessment of a standard treatment protocol was formulated for all the players with deficient and insufficient vitamin D3 levels. They were as follows. Calcitriol sachet once weekly for one month was prescribed for all players with vitamin D3 deficiency and insufficiency along with Architol injection $6 \mathrm{~L}$ unit's intramuscular. The number of injections varied according to the level of deficiency.

Players with vitamin D3 $<20 \mathrm{ng} / \mathrm{ml}$ were given 3 IM injections (per week 1 injection)

Between 20-30, ng/ml were given 2 IM injections (per week 1 injection)

Between 30-40, ng/ml were given 1 IM injection

Duration of medications was set for 4 weeks during which players continued with their routine football training. Sidekick distance, instep kick distance and kick velocity were assessed pre and immediately post 4 weeks of supplementation. Post 4 weeks 19 players were eliminated from the study due to inability to maintain follow-up with the medications, hence 131 players were reassessed for their performance parameters. The permission for the study was taken from the Research Review Committee of NMIMS, Mumbai. 


\section{Performance Parameters}

1. Kick distance: Procedure: Spot kick was the method used to assess kick distance. There were 2 ways in which kick distance was performed which were sidekick (figure 1) and instep kick (figure 2). Each kick was performed thrice and the best score was taken into consideration. All the kicks were performed at $0^{\circ}$ approach angle with two steps to a stationary ball towards a target. Scoring: Distance was assessed (in meters) from the point of a kick to the point where the ball made the first contact and a measuring tape was used to measure the same.

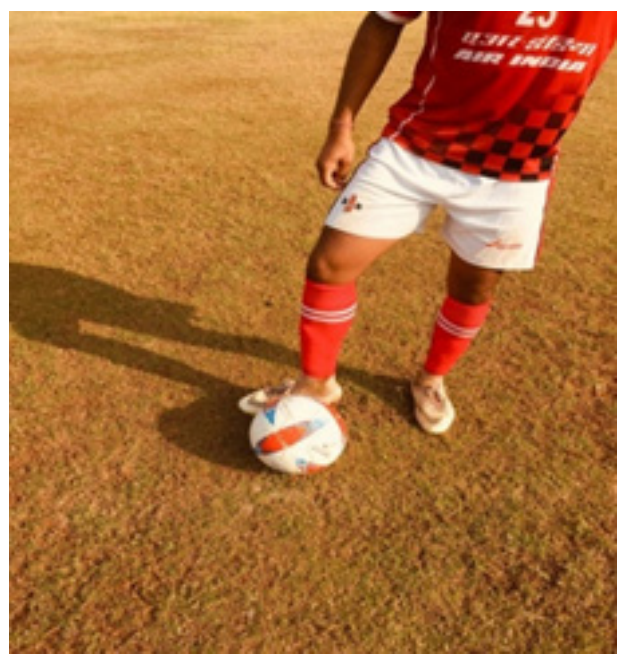

Figure 1: Sidekick distance.

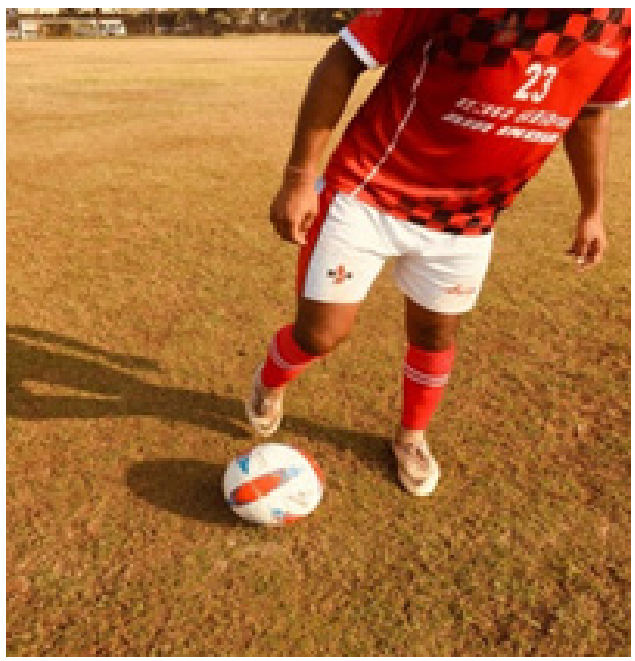

Figure 2: In stepkick distance.

2. Kick velocity: Kick velocity was assessed using Bushnell velocity speed gun radar (figure 3). The radar was held by the assessor half a meter behind the player (figure 4). The trigger was engaged on the initiation of the kick. Once the kick was complete the trigger was released. On releasing the trigger, the maximum speed gets reflected on the radar. The test was performed thrice and the best score was taken into consideration. Speed was calculated in Kilometer Per Hour (Kph).

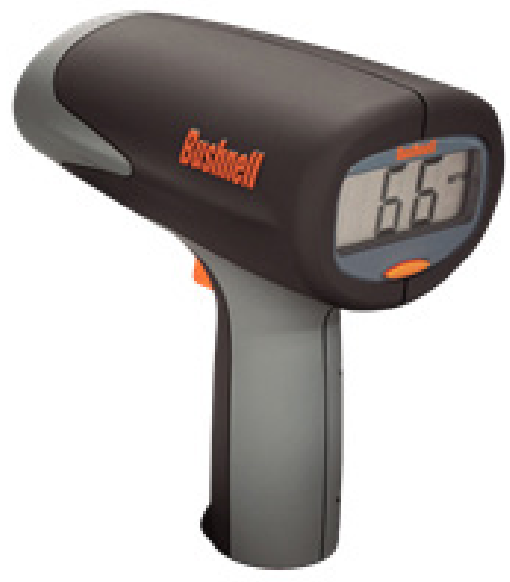

Figure 3: Bushnell velocity speed gun radar.

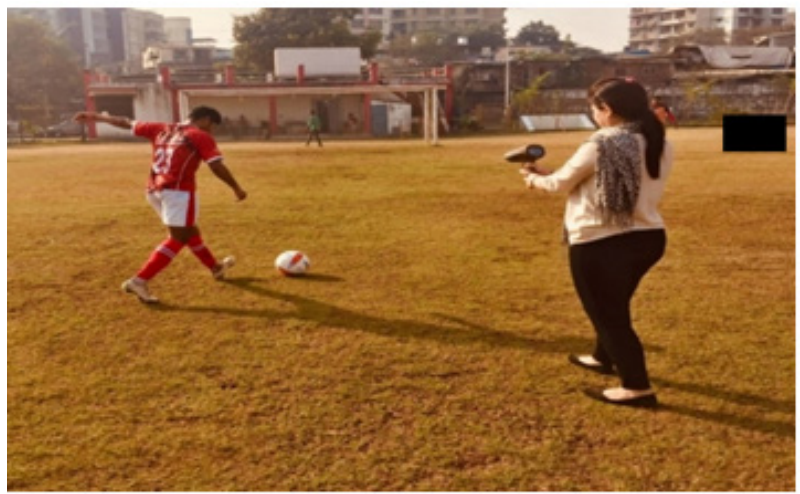

Figure 4: Assessment of kick velocity.

\section{Statistical analysis}

Data was updated in Microsoft EXCEL-2010. Data were analyzed using SPSS 23 software package for statistical analysis. The level of significance was set at $p<0.05$. Sidekick distance, instep kick distance and kick velocity were calculated for their mean and standard deviation. Comparison of mean was done using paired t-test. Pearson correlation was used to identify the correlation between the variable.

\section{RESULTS}

The players had a mean age of $22.97 \pm 4.26$ years. About $69 \%$ of players were between the age group of 18-24 years (figure 5). The mean vitamin $\mathrm{D} 3$ level in $\mathrm{ng} / \mathrm{ml}$ was $21.53 \pm 6.13$. About $87 \%$ of players recorded a vitamin D3 less than 30 $\mathrm{ng} / \mathrm{ml}$ and $99 \%$ players recorded a vitamin D3 less than 40 $\mathrm{ng} / \mathrm{ml}$ (Figure 6,7). 


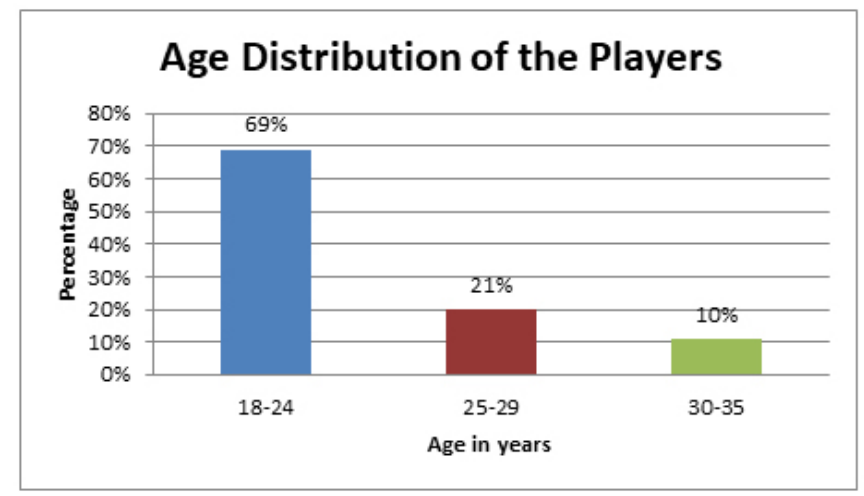

Figure 5: Age distribution of the players.

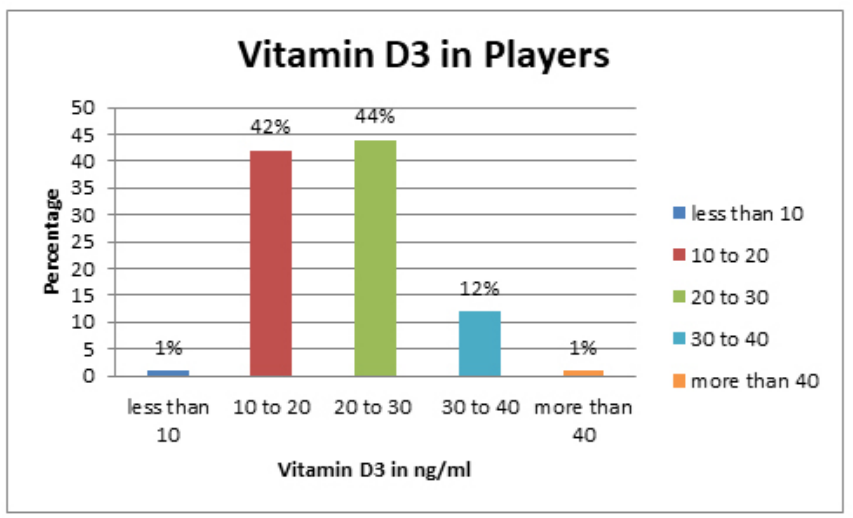

Figure 6: Vitamin D3 levels in players.

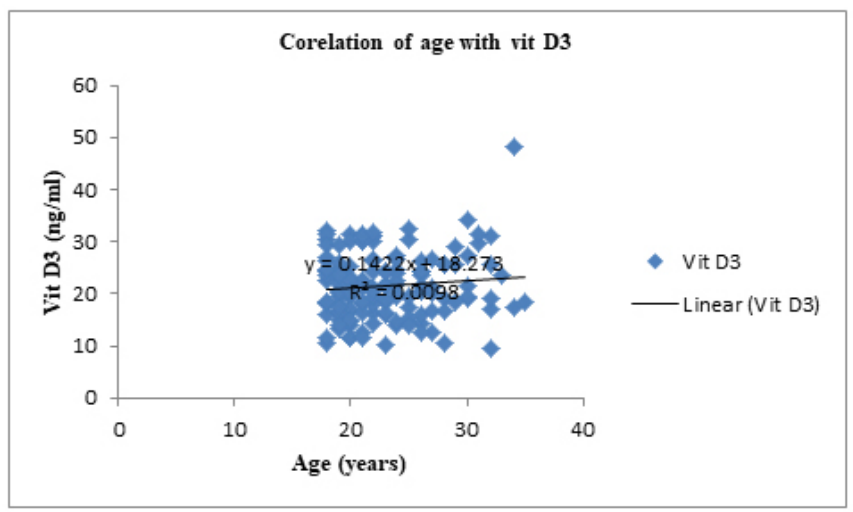

Figure 7: Correlation of age with vitamin D3 $(r=0.09)$.

When players were analysed for sidekick distance, their pre supplementation sidekick distance was $35.88 \pm 7.40$ and post supplementation sidekick distance were $41.14 \pm 6.56$ (figure 8). Mean difference was $5.30 \pm 3.44$ (table 2). On comparison, there was a significant difference as $\mathrm{t}=-17.38$ and $\mathrm{p}<0.05$ (table 2).
Table 2: Comparison of sidekick distance pre and post supplementation

\section{Mean SD t-Value P-Value Inference}

$\begin{array}{llllll}\begin{array}{l}\text { Pre Supple- } \\ \text { mentation }\end{array} & 35.88 & 7.40 & -17.38 & <0.05 & \text { Statistically } \\ & & & & & \text { Significant }\end{array}$

Post Suppl-

ementation $\quad 41.14 \quad 6.56$

Difference $\quad 5 \cdot 30 \quad 3.44$

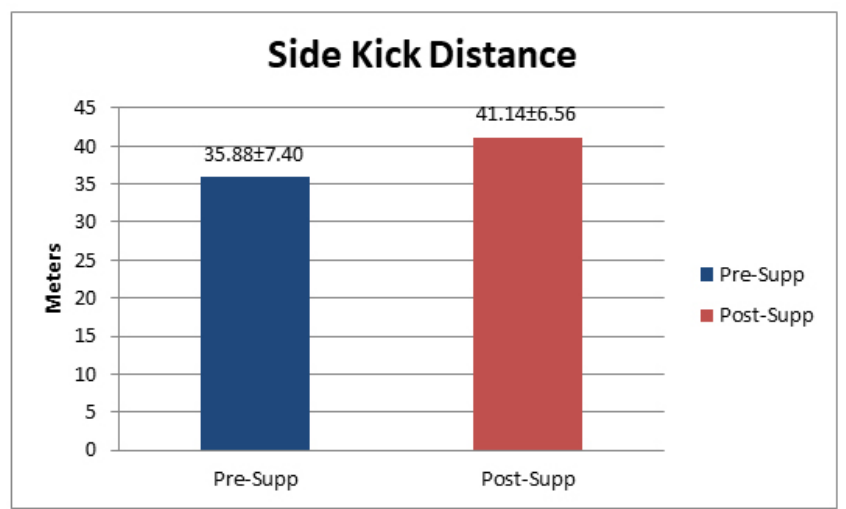

Figure 8: Difference in sidekick distance (meters) pre and post supplementation

Table 3: Comparison of instep kick distance pre and post supplementation

\section{Mean SD t-Value P-Value Inference}

Pre Supple- $\quad 37.35 \quad 6.88$

mentation

\begin{tabular}{lrrrrr}
$\begin{array}{l}\text { Post Supple- } \\
\text { mentation }\end{array}$ & 42.60 & 6.43 & -15.83 & $<0.05$ & Statistically \\
Difference & 5.28 & 3.28 & & & \\
\hline
\end{tabular}

When players were analysed for instep kick distance, their pre supplementation instep kick distance was $37.35 \pm 6.88$ and post supplementation instep kick distance was $42.60 \pm 6.43$ (Figure 9). Mean difference was 5.28 \pm 3.28 (table 3). On comparison, there was a significant difference as $\mathrm{t}=-15.83$ and $\mathrm{p}<0.05$ (Table 8). 


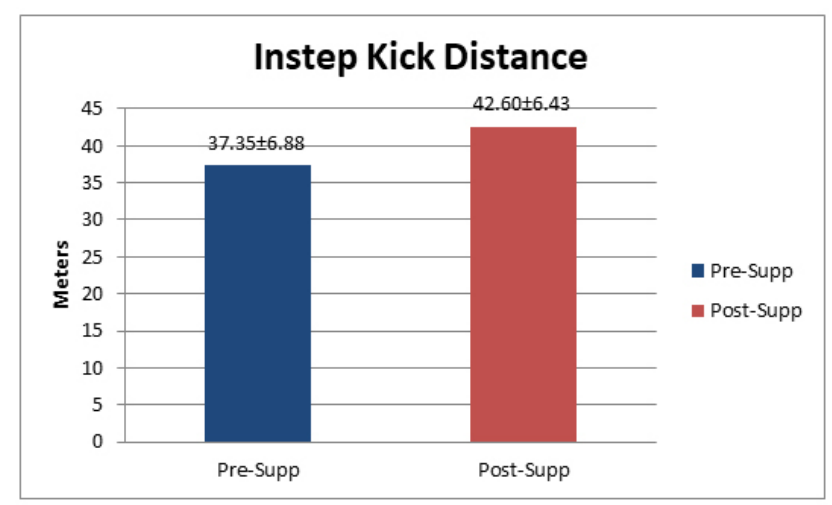

Figure 9: Difference in instep kick distance (meters) pre and post supplementation.

Table 4: Comparison of kick velocity pre and post supplementation

\begin{tabular}{lcccl} 
& Mean & DT-Value & P-Value & Inference \\
$\begin{array}{l}\text { Pre Supple- } \\
\text { mentation }\end{array}$ & 70.64 & -10.80 & $<0.05$ & Statistically \\
$\begin{array}{l}\text { Post Supple- } \\
\text { mentation }\end{array}$ & 82.42 & & & Significant \\
Difference & 11.84 & & & \\
\hline
\end{tabular}

When players were analysed for kick velocity, their pre supplementation kick velocity was $70.64 \pm 13.20$ and post supplementation kick velocity was 82.42 \pm 7.22 (figure 10). Mean difference was $11.84 \pm 12.51$ (table 4 ). On comparison, there was a significant difference as $\mathrm{t}=-10.80$ and $\mathrm{p}<0.05$ (table 9 and 10).

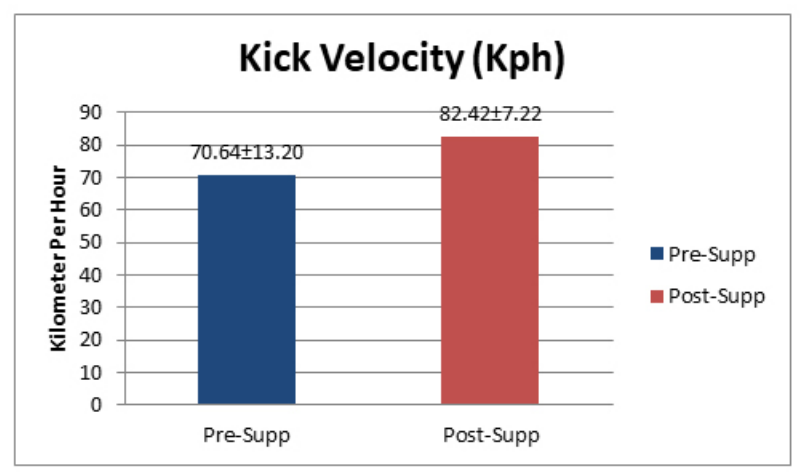

Figure 10: Difference in kick velocity (Kph) pre and post supplementation.

\section{DISCUSSION}

In this study, 150 players from different football clubs and football academies across Mumbai city were evaluated for their vitamin D3 status. As seen in figure 5 maximum players $(69 \%)$ were between the age group of 18-24 years $21 \%$ were between $25-29$ years and only $10 \%$ were above 30 years of age. Mean vitamin D3 levels were found to be $21.53 \pm 6.13 .87 \%$ players had vitamin $\mathrm{D} 3<30 \mathrm{ng} / \mathrm{ml}$ and $99 \%$ players in the present study had vitamin D3 $<40 \mathrm{ng} / \mathrm{ml}$ (figure 6). These findings were similar to a study done by Pravin shah et al finding out the vitamin D deficiency prevalence in healthy subjects. After assessing 178 subjects they concluded that vitamin D deficiency was reported by $94.94 \%$ and insufficiency by $5.06 \%$ subjects. ${ }^{12}$ Another study conducted by Marwaha et $\mathrm{al}^{13}$ on healthy Indians showed that vitamin $\mathrm{D}$ deficiency was reported in $91.2 \%$ subjects above the age of 50 years and $6.8 \%$ were reported as being insufficient. Arya et al., (2004) has reported that $67 \%$ of young healthy individuals have a vitamin D level $<15 \mathrm{ng} / \mathrm{ml}$ whereas Harinarayan et al (2004) has reported a prevalence of $62 \%$ in urban adults in their population-based study in Andhra Pradesh. This is in contrast to a cross-sectional study by Mitra et $\mathrm{a}{ }^{14}{ }^{14} \mathrm{done}$ on the footballers of Tata Football Academy (TFA), Jamshedpur found a prevalence rate of only $2.1 \%$. This discrepancy in the findings could be due to the low cut-off values of vitamin $D$ selected in the above study. ${ }^{10-14}$

In the present study post 4 weeks of vitamin D3 supplementation sidekick distance improved from $35.88 \pm 7.40$ to $41.14 \pm 6.56$, instep kick distance improved from $37.35 \pm 6.88$ to $42.60 \pm 6.43$ and kick velocity improved from $70.64 \pm 13.20$ to $84.42 \pm 7.22$. As the tendency of developing vitamin $\mathrm{D}$ toxicity is very rare, players were prescribed with aggressive supplementations of vitamin D3. A study by Close et al. ${ }^{5}$ was performed on interventional and placebo group of 10 elite level football players. Both the groups on receiving either a placebo or $5000 \mathrm{IU} /$ day of vitamin D found that in the interventional group there was an increase in power of the lower limbs post 8 weeks of supplementation. They reported an increase in the $10 \mathrm{M}$ sprint test and vertical jump test in the experimental group receiving vitamin $\mathrm{D}$. There was also an increment noted in the serum vitamin D levels of the experimental group compared to their placebo counterparts. They concluded that lower vitamin D levels are one of the major causes of reduced exercise capabilities in athletes. ${ }^{13,14}$

Improvement in skeletal muscle contraction has been observed with higher levels of vitamin $\mathrm{D}^{15,16}$ causes activation of vitamin D receptors on the skeletal muscle tissue thereby improving power in skeletal muscles. Type II muscle fibres which are the fast-twitch muscle fibres particularly respond to the levels of vitamin D. It is a well-known fact that low vitamin $\mathrm{D}$ levels result in a reduction in number and size of these fibres. These fast-twitch muscle fibres are crucial for peak sports performance as they play a vital role in sprinting, power kicking and running. ${ }^{17}$ Low vitamin $\mathrm{D}$ levels result in atrophy of these fibres. Additionally, the atrophy can be reversed with supplementation. Optimal vitamin D levels have also been known to increase intestinal absorption of calcium 
thereby increasing the levels of serum calcium. This in turn improves bone mineralization thereby increasing bone mineral density. Such improvements can lower the risk of falls by $20 \%$ in athletes with adequate supplementation thereby reducing the risk of stress fractures. ${ }^{17,18}$ Activation of osteoclasts in the bone is seen due to an increase in the levels of parathyroid hormone caused by vitamin $\mathrm{D}$ concentration of $<30 \mathrm{ng} / \mathrm{ml}$.

Vitamin D3 deficiency is known to cause skeletal muscle weakness. Vitamin D3 is known to regulate muscle protein synthesis thereby having an impact on muscle mass. ${ }^{18}$ The expression and activation of vitamin D receptors require sufficient levels of vitamin D.

\section{Limitations of the Study}

Post supplementation blood test was not conducted in the present study; hence the improvements in terms of vitamin D3 levels could not be recorded.

\section{Clinical Recommendations}

On an annual basis, vitamin D levels should be mandatorily checked for all the player's Supplementations should be made available thereby reducing the risk of injuries and improving athletic performance. Coaches, team managers and players should be made aware of the importance of vitamin $\mathrm{D}$ considering it to be the most underdiagnosed and undertreated nutritional deficiency.

\section{Future Scope of Study}

Future studies are required to understand the optimal vitamin $\mathrm{D}$ treatment regimes in the athletic population to maximize performance. Moreover, literature shows wide inconsistency concerning cut-off values of vitamin D hence further studies are required to determine the adequate cut-off values to ensure peak performance.

\section{CONCLUSION}

We concluded that the vitamin D3 level in professional football players in Mumbai City is far below optimal. Supplementation may improve their kicking performance and speed. Especially for football players, an optimal condition of their muscles is imperative for peak performance. Supplementation in case of deficiency of vitamin D3 may help improve the athletic performance of these players.

\section{ACKNOWLEDGEMENT}

The authors would like to thank General Diagnostics Pvt. Ltd. for their assistance with the serum vitamin D3 assessment. Authors acknowledge the kind cooperation received from the team coaches and players throughout the study. Authors also acknowledge the immense help received from the scholars whose articles are cited and included in the reference of this manuscript.

\section{Conflict of Interest: None}

Financial support: None

\section{REFERENCES}

1. Bangsbo J, Mohr M, Krustrup P. Physical and metabolic demands of training and match-play in the elite football player. J Sports Sci 2006;24(07):665-674.

2. Wisloff U, Castagna C, Helgerud J, et al. Strong correlation of maximal squat strength with sprint performance and vertical jump height in elite soccer players. Br J Sports Med 2004;38:285-8.

3. Van School NM, Lips P. Worldwide vitamin D status. Best Pract Res Clin Endocrinol Metab 2011;20:1807-20.

4. Mithal A, Wahl DA, Bonjour JP. Global Vitamin D status and determinants of hypovitaminosis D. Osteoporos Int. 2009;20:18071820 .

5. Cannell JJ, Hollis BW, Zasloff M, Heaney RP. Diagnosis and treatment of vitamin D deficiency. Expert Opin Pharmacother 2008; 9:107Y18.

6. Srimani S, Saha I, Chaudhuri D. Prevalence and association of metabolic syndrome and vitamin D deficiency among post menopausal women in a rural block of West Bengal, India. PLoS One. 2017;12(11):e0188331.

7. Holick MF. Vitamin D deficiency. $N$ Engl J Med. 2007;357(3):266-281.

8. Armas LA, Dowell S, Akhter M. Ultraviolet-B radiation increases serum 25-hydroxyvitamin D levels: the effect of UVB dose and skin colour. J Am Acad Dermatol 2007;57(4):588-593.

9. Dawson-Hughes B, Heaney RP, Holick MF, Lips P, Meunier PJ, Vieth R. Estimates of optimal Vitamin D status. Osteoporos Int 2005;16:713-6.

10. Bischoff-Ferrari HA, Dietrich T, Orav EJ, Dawson-Hughes B. Positive association between 25-hydroxy vitamin D levels and bone mineral density: a population-based study of younger and older adults. Am J Med 2004; 116(9) :634- 639.

11. Heaney RP. Vitamin D: criteria for safety and efficacy. Nutr Rev 2008; 66(10): S178 - S181.

12. Ritu G, Gupta A. Vitamin D Deficiency in India: Prevalence, Causalities and Interventions. Nutrients. 2014 Feb; 6(2): 729775 .

13. Marwaha RK, Tandon N, Garg MK, Kanwar R, Narang A, Sastry A. Vitamin D status in healthy Indians aged 50 years and above. J Assoc Physicians India 2011;59:706-709.

14. Mitra Sm. Tata steel executives have a lower prevalence of Vitamin D deficiency and comparable prevalence of Vitamin B12 deficiency concerning reported rates in the Indian population. Ind J Sci Res Tech 2015; 3(5):72-79.

15. Close GL, Russell J, Cobley JN, Owens DJ, Wilson G, Fraser WD, et al. Assessment of vitamin D concentration in non-supplemented professional athletes and healthy adults during the winter months in the UK: implications for skeletal muscle function. J Sports Sci 2013;31:344-53.

16. Ogan D, Pritchett K. Vitamin D and the athlete: risks, recommendations, and benefits. Nutrients 2013;5(6):1856-1868.

17. Todd JJ, Pourshahidi KL, McSorley EM, Madigan SM, Magee PJ. Vitamin D: Recent advances and implications for athletes. Sports Med 2015;45:213-29.

18. Bischoff-Ferrari HA, Giovannucci E, Willett WC, Dietrich T, Dawson-Hughes B. Estimation of optimal serum concentrations of 25-hydroxyvitamin D for multiple health outcomes. Am J Clin Nutr 2006;84:18-28. 